\title{
WIRELESS SENSOR NETWORK FOR ENVIRONMENTAL MONITORING IN HILL AREAS AS A PREVENTIVE MEASURE OF GLOBAL WARMING
}

\author{
Dr. Hare Ram Singh, \\ Department of Computer Science and Engineering, \\ CRK Polytechnic College, \\ Hajipur, Bihar, India. \\ hrsingh.2000.2000@gmail.com
}

\begin{abstract}
Wireless Sensor Network (WSN) is used in various applications such as area monitoring, healthcare monitoring, industrial and environmental monitoring and so on. Spatially dispersing various sensors and creating a network for knowing the physical conditions of the environment is known as WSN. In this paper, WSN is created for monitoring the environment in hill areas for detecting the various abnormalities such as forest fire, deforestation and landslides. Long Range (LoRa) low power wireless technology and sensors for monitoring forest fire, deforestation and landslides are used in WSN. The data collected in the central point is processed for further evaluation and alerts the authorities through SMS and internet. Global System for Mobile (GSM) Communication modem with Global Packet Radio System (GPRS) enabled SIM card is used for enabling internet service for the central data collecting unit. The system is powered from battery which is recharged by electrical energy converted from solar energy using solar panel.
\end{abstract}

Keywords: Hill environment monitoring, WSN, deforestation, forest fire, landslides, LoRa, global warming.

\section{INTRODUCTION}

The average annual temperature of the earth surface increases every year. This phenomenon is known as global warming. Rising sea levels, precipitation changes, Ocean acidification, heat waves and expansion of deserts are few of the effects of global warming. United Nations Framework Convention on Climate Change (UNFCCC) is doing research on climate change and the main objective of UNFCCC is to prevent dangerous anthropogenic interference with the climate system [1]. Deforestation and forest degradation are responsible for around $15 \%$ of all greenhouse gas emissions [2] and contributes to global warming [3].

Technology based solutions will helps to monitor and control deforestation and forest fire. Developments in wireless technology make it possible to form a wireless network for real time monitoring of environmental conditions. Understanding of physical environment and deployment is necessary before designing a network. Huge amount of data will be transferred from sensor network to data repository and these data will give information about the environment. Monitoring system for a glacial environment has been developed in the Envisense Glacs Web project for getting valuable information about the global warming and climate change [4].

Global satellite based communication system, year round manual measurements and manually taped data loggers are difficult in terrestrial higharctic ecosystems. To addresses these challenges WSN based data acquisition system has been designed. Water quality parameters such as conductivity, temperature, depth, dissolved oxygen, chlorophyll, and turbidity are measured 
and logged in this system [5]. Indoor air quality monitoring WSN has been designed in [6] for monitoring various air pollutants such as $\mathrm{CO}, \mathrm{CO} 2, \mathrm{O} 3, \mathrm{No} 2$, $\mathrm{SO} 2$, particulate matters and volatile organic compound. Environmental parameters such as carbon dioxide, oxygen, temperature and humidity levels are monitored in [7] using ZigBee based sensor network.

WSN for monitoring a home environment is being designed in [8]. It senses and informs about various conditions inside the home such as gas leak, fire accident, theft and On/Off conditions of home appliances. ZigBee protocol is used in designing the wireless network. Microclimate monitoring for forest ecosystems is discussed in [9]. In this study, experiments are carried in two forest ecosystems in China using WSN. Temperature and humidity parameters are measured and analyzed against standard meteorological data.

The system proposed here is about designing a WSN for hill areas to monitor the deforestation, forest fire and microclimatic conditions. It uses Internet of Things (IoT) and cloud system for receiving, storing and analyzing the data. Many industries are adapting to Internet of Things (IoT) due to the transformations of digital technologies. Growing network bandwidth, smaller, cheaper and more accurate sensors, and increased computing power and cheaper storage are decisively fuel the IoT evolution [10].

In this study, WSN is designed for environmental monitoring in hill areas is presented. The organization of this study is as follows: Section 2 describes the overview of system architecture with different nodes and gateways. Section 3 shows the testing of sensors and reading of various parameters. The last section concludes the WSN system for environmental monitoring in hill areas.

\section{METHODS AND MATERIALS}

The overall view of the proposed WSN for hill area environment monitoring is shown in Fig. 1. It consists of wireless sensor nodes, gateway and remote server. Monitoring stations can be personal computer (PC), laptops or mobile phones.

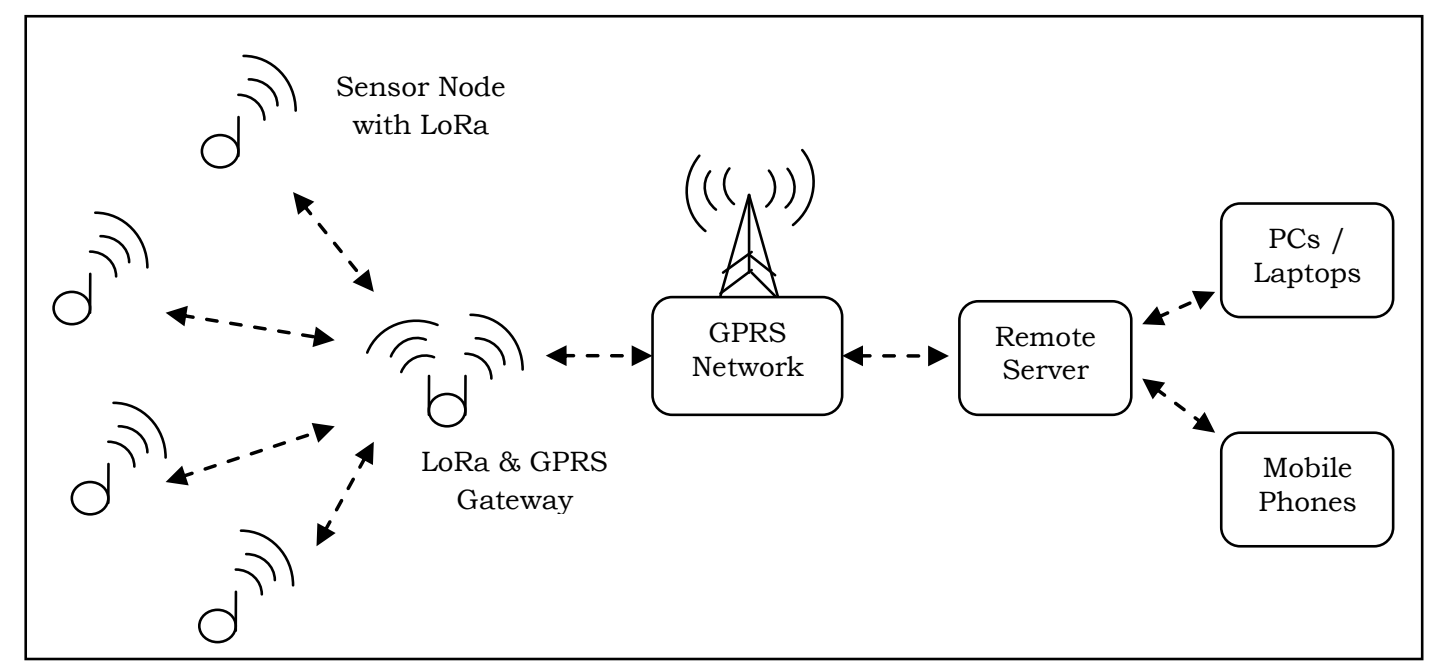

Fig. 1 Overview of System Architecture

The sensor nodes use low power long range wireless technology for wireless communication with gateway unit. Gateway unit uses GPRS network for enabling 
internet connection to it. Through this GPRS network it uploads the sensor data to remote server. Gateway unit acts as middleman between sensor nodes and remote server. The loaded information about the hill environment can be retrieved at client nodes or monitoring stations using android application. Small round shaped part with antenna symbol, in Fig. 1 from left to right, represents the sensor node. The same structure with dual antenna symbol represents the gateway unit which consists of LoRa and GPRS.

IoT is giving way for the introduction of lots of technology into the market. The key challenge in IoT is, devices or things needs to be able to communicate with internet. WiFi is available for this, but needs more power. LoRa is a low power physical layer which can be used for long range wireless communication with optimized energy efficiency and the robust signal. It is more suitable for battery operated wireless applications. The key features of this technology are low cost, low power consumption, long range, secure, standardized and high capacity [11-12].

\section{A. Wireless Sensor Node and Gateway}

Figure 2 shows the block diagram of one of the wireless sensor node and Figure 3 shows the block diagram of gateway unit. Figure 4 shows how the power is generated using solar panel and delivered to devices.

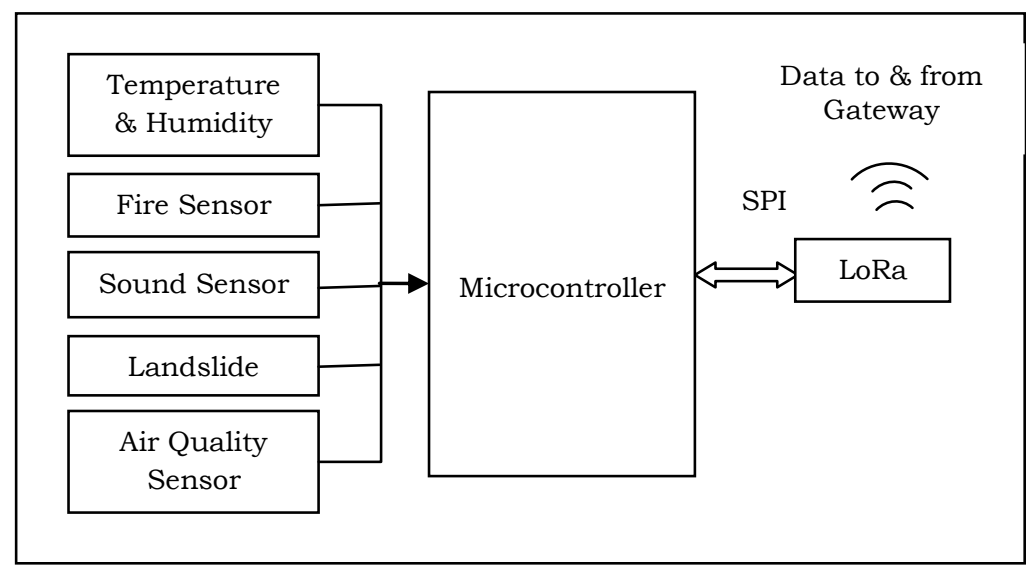

Fig. 2 Wireless sensor node

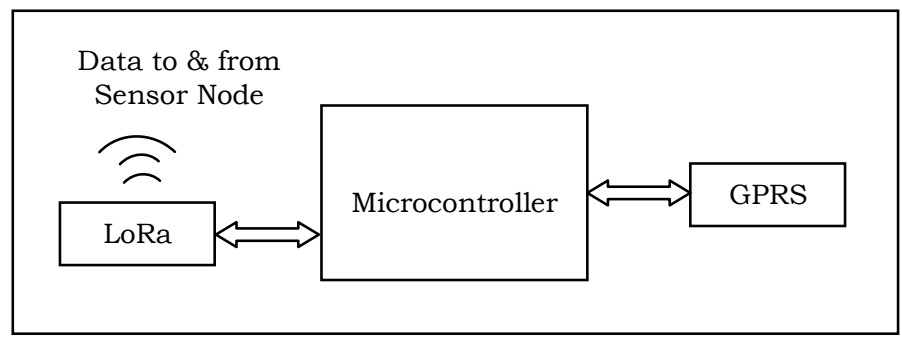

Fig. 3 LoRa \& GPRS gateway

As Fig. 2 depicts each sensor node consists of various sensors and are read by microcontroller. Through LoRa the sensor information are passed to gateway. DHT11 is chosen for sensing microclimatic condition such as temperature and humidity. Micro electro mechanical system based microphone 
and accelerometer are used for sensing sounds during deforestation and land movements during landslides. Corbon monoxide and carbon dioxide are measured to know the quality of air, which can help to identify degradation of woods. GSM modem with GPRS enabled SIM card is used for internet connection [13] to the gateway unit as shown in Fig. 3. Through this internet connection, data received from various sensor nodes via LoRa wireless transceiver are uploaded to remote server.

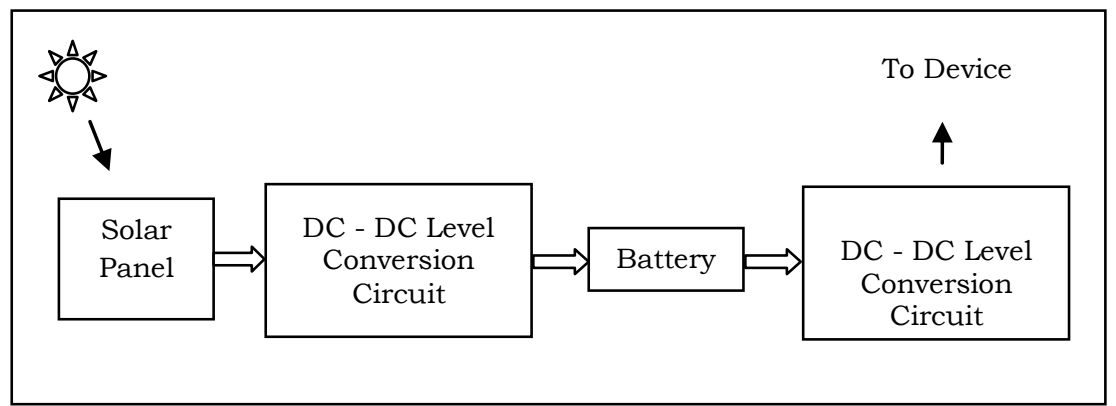

Fig. 4 Power circuit

As Fig. 4 shows, the solar energy is converted to electrical energy using solar panel and it is converted to the level required to store in battery. The stored energy from battery is again converted to various level required by each individual device and delivered to it. All sensor nodes and gateway unit can be fitted with this renewable energy source.

\section{RESULTS AND DISCUSSION}

Solar energy operated WSN is designed with various sensors, Arduino mega 2560 and LoRa wireless transceiver. Arduino Mega 2560 is an ATmega 2560 microcontroller based development board. This microcontroller is having 54 pins which include 16 analog pins [14]. It is chosen because the sensor node may require more analog pins and digital pins. Initially the sensors are tested for their accuracy and to know the threshold values for various abnormal cases. The cases are stimulated and its corresponding readings are taken from sensors using test coding and Realterm serial data reading software. It is shown in Fig. 5 and Fig. 6. Similarly the maximum distance for proper wireless communication is tested in open area between two wireless nodes.

Blynk IoT platform is used as cloud server for data storing and its supported mobile application is used for data monitoring and control if need. Internet is necessary at both ends such as device and mobile phone. Once the device is ON and it is connected to blynk cloud server platform, it can be accessed from mobile phone for getting live sensor readings and history. Monitoring is possible from only one mobile device for security reasons. It is possible using the authentication token generated for the particular mobile phone. 


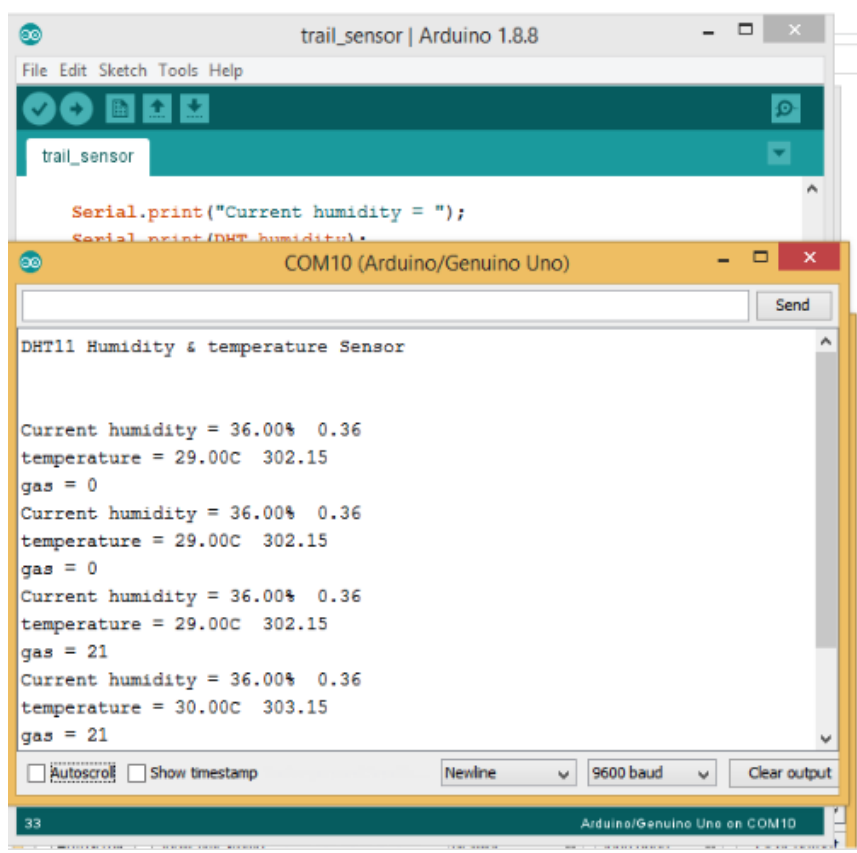

Fig. 5 Testing of sensors and reading threshold values using serial monitor

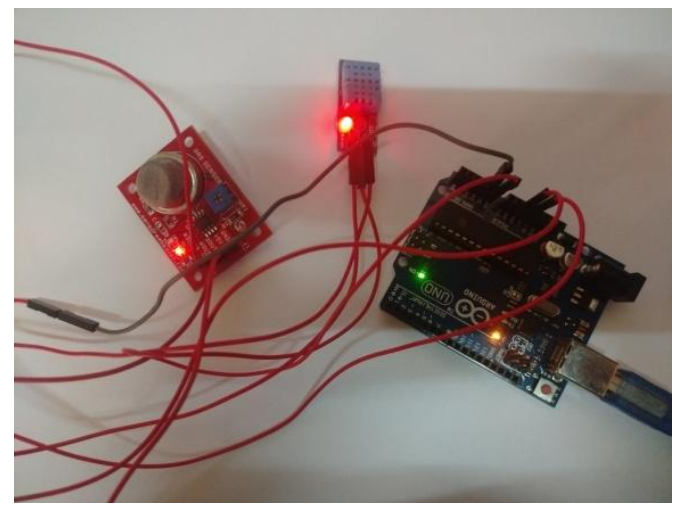

Fig. 6 Hardware Testing

\section{CONCLUSION}

The device for hill areas environmental conditions monitoring is designed with 3 sensor nodes and 1 gateway unit. The performance and reliability of the system, battery life, power consumption for each data transmission are tested. The system effectively updates the microclimatic condition in the remote server at the set interval. Also instant alerts are raised by the system for various abnormal cases such as forest fire, illegal tree cutting and landslides. The results show that, the data will be very helpful in analyzing the physical conditions of the environment. The air quality parameters can help to identify the degradation and instant alerts can help the forest officers to take the immediate remedies. This way the system can be an effective preventive measure for global warming. And the additional landslide alert can help the officers for fast clearance and the travelers to take alternate route if any available. 


\section{REFERENCES}

[1]. https://en.wikipedia.org/wiki/Global_warming

[2]. https://www.worldwildlife.org/threats/deforestation-and-forestdegradation

[3]. https://www.scientificamerican.com/article/deforestation-and-globalwarming/

[4]. K. Martinez, J.K. Hart, and R. Ong, "Environmental sensor networks", Computer, Vol. 37, No. 8, 2004, pp. 50-56.

[5]. M. Chang, and P. Bonnet, "Monitoring in a high-arctic environment: some lessons from MANA", IEEE Pervasive Computing, Vol. 9, No. 4, 2010, pp. 16-23.

[6]. J.Y. Kim, C.H. Chu, and S.M. Shin, "ISSAQ: An integrated sensing systems for real-time indoor air quality monitoring", IEEE Sensors Journal, Vol. 14, No. 12 , 2014, pp. 4230-4244.

[7]. A. Abdullah, O. Sidek, N.A. Amran, U.N. Za'Bah, F. Nikmat, H. Jafar, and M.A. Hadi, "Development of wireless sensor network for monitoring global warming", International Conference on Advanced Computer Science and Information Systems, 2012, pp. 107-111.

[8]. R. Pandiaraj, "Smart internet connected mobile phone remote for monitoring and controlling of house and household appliances", International Journal of Advances in Signal and Image Sciences, Vol. 3, No. 2, 2017, pp. 14-20.

[9]. J. Jin, Y. Wang, H. Jiang, and X. Chen, "Evaluation of Microclimatic Detection by a Wireless Sensor Network in Forest Ecosystems", Scientific reports, Vol. 8, No. 1, 2018.

[10]. S. Andreev, and C. Dobre, "The Internet of Things and Sensor Networks", IEEE Communications Magazine, Vol. 57, No. 9, pp. 70-70.

[11]. https://www.murata.com/en-sg/products/connectivitymodule/lpwa/lora

[12]. https://www.digikey.in/en/maker/blogs/introduction-to-lora-technology

[13]. SIM900, A. T. (2010). Command Manual.

[14]. https://store.arduino.cc/usa/mega-2560-r3 